\title{
The Kinetics of Phase Transformation in Welds
}

\author{
J. W. Elmer, J. Wong, T. Palmer
}

February 6, 2002

U.S. Department of Energy

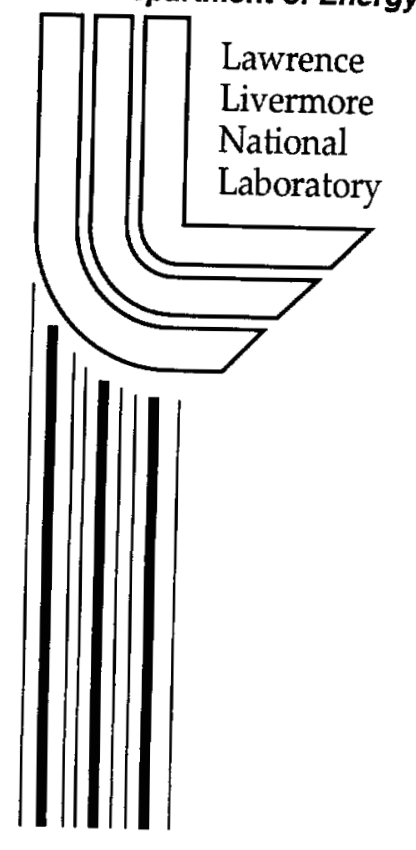

Approved for public release; further dissemination unlimited 


\section{DISCLAIMER}

This document was prepared as an account of work sponsored by an agency of the United States Government. Neither the United States Government nor the University of California nor any of their employees, makes any warranty, express or implied, or assumes any legal liability or responsibility for the accuracy, completeness, or usefulness of any information, apparatus, product, or process disclosed, or represents that its use would not infringe privately owned rights. Reference herein to any specific commercial product, process, or service by trade name, trademark, manufacturer, or otherwise, does not necessarily constitute or imply its endorsement, recommendation, or favoring by the United States Government or the University of California. The views and opinions of authors expressed herein do not necessarily state or reflect those of the United States Government or the University of California, and shall not be used for advertising or product endorsement purposes.

This work was performed under the auspices of the U. S. Department of Energy by the University of California, Lawrence Livermore National Laboratory under Contract No. W-7405-Eng-48.

This report has been reproduced directly from the best available copy.

Available electronically at http://www.doc.gov/bridge

Available for a processing fee to U.S. Department of Energy

And its contractors in paper from

U.S. Department of Energy

Office of Scientific and Technical Information P.O. Box 62

Oak Ridge, TN 37831-0062

Telephone: (865) 576-8401

Facsimile: (865) 576-5728

E-mail: reports@adonis.osti.gov

Available for the sale to the public from

U.S. Department of Commerce

National Technical Information Service

5285 Port Royal Road

Springfield, VA 22161

Telephone: (800) 553-6847

Facsimile: (703) 605-6900

E-mail: orders@ntis.fedworld.gov

Online ordering: http://www.ntis.gov/ordering.htm

OR

Lawrence Livermore National Laboratory

Technical Information Department's Digital Library

http://www.llnl.gov/tid/Library.html 


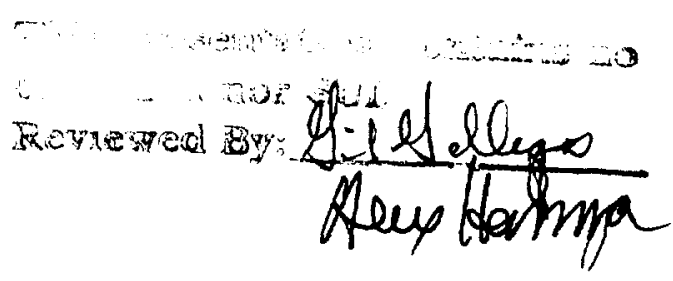

\title{
The Kinetics of Phase Transformation in Welds
}

\author{
Principal Investigator: J. W. Elmer, Co-Investigators: Joe Wong, Todd Palmer
}

\author{
Section A: Accomplishments FY98 - FY01
}

Purpose - The fundamentals of welding-induced phase transformations in metals and alloys are being investigated using a combination of advanced synchrotron-based experimental methods and modem computational science tools. In-situ experimental methods have been developed using a spatially resolved $x$-ray probe to enable direct observations of phase transformations under the real non-isothermal conditions experienced during welding. These experimental techniques represent a major step forward in the understanding of phase transformations that occur during welding, and are now being used to aid in the development of models to predict microstructural evolution under the severe temperature gradients, high peak temperatures and rapid thermal fluctuations characteristic of welds. Titanium alloys, stainless steels and plain carbon steels are currently under investigation, and the phase transformation data being obtained here cannot be predicted or measured using conventional metallurgical approaches.

Two principal synchrotron-based techniques have been developed and refined for in-situ investigations of phase transformation dynamics in the heat-affected zone (HAZ) and fusion zone (FZ) of welds: Spatially Resolved X-Ray Diffraction (SRXRD) and Time Resolved X-Ray Diffraction (TRXRD). Both techniques provide realtime observations of phases that exist during welding, and both have been developed at the Stanford Synchrotron Radiation Laboratory (SSRL) using a high flux wiggler beam line.

The SRXRD technique enables direct observations of the phases existing in the HAZ of quasistationary moving arc welds, and is used to map the HAZ phases by sequentially jogging the weld with respect to the xray beam while taking xray diffraction (XRD) patterns at each new location. These spatially resolved XRD patterns are collected in linear traverses perpendicular to the direction of weld travel. The XRD data contained in multiple traverses is later compiled to produce an areal map of the phases that existed in the HAZ during welding.

The TRXRD technique uses an $\mathrm{x}$-ray beam positioned at one location, where XRD patterns are collected as a stationary 'spot' weld rapidly heats and cools the base metal. Data can be collected from either the HAZ to observe solid-state phase transformations or from the FZ to observe solidification and subsequent solid-state phase transformations. Higher heating and cooling rates are produced in the spot welds than in the moving welds, requiring time resolution in the milli-second regime for TRXRD to record the rapid microstructural changes that occur.

Numerical weld modeling is being performed to: 1) extract the important phase transformation kinetic information from the experimental data, 2) investigate mechanisms of phase transformations under non-isothermal welding conditions, and 3) develop models for predicting weld microstructural evolution. The core of our numerical weld 
modeling program is a 3-dimensional coupled heat and fluid flow code developed by the Penn State University. Additional modeling is being performed at Oak Ridge National Laboratory where Thermocalc is being used to understand phase equilibria in complex alloy systems, and where a diffusion-based model considering paraequilibrium is being developed to predict phase transformations in steels.

Technical Progress - FYOO Synchrotron-based experiments. SRXRD and TRXRD were used to investigate real time solidification and solid state transformations during welding of AISI 1005 carbon manganese steel, alloy 2205 duplex stainless steel (DSS), and a flux cored arc welding alloy (FCAW). The welding experiments were conducted in-situ at the Stanford Synchrotron Radiation Laboratory (SSRL) using the high-flux $*$ ray wiggler beam line 10-2. SRXRD phase transformation mapping with $250 \mu \mathrm{m}$ spatial resolution was completed on AISI 1005 C-Mn steel and on alloy 2205 DSS, and produced a detailed phase transformation map for each of these alloy systems. TRXRD investigations of solidification dynamics were conducted on the FCAW alloy with $50 \mathrm{~ms}$ temporal resolution. These TRXRD experiments are aimed at investigating the influence of solidification rate on the formation of non-equilibrium solidification that occurs only at high cooling rates in this alloy, and were performed in collaboration with S. A. David and S. Babu of ORNL and M. Quintana of the Lincoln Electric Company.

FY0O Numerical Modeling. Microstructural features in commercially pure titanium weldments were modeled for the first time using a combination of transport phenomena, phase transformation theory, and experimental SRXRD data. A three-dimensional, turbulent heat transfer and fluid flow model was developed to calculate the temperature and velocity fields, thermal cycles, and the shape and size of the fusion zone of quasisteady-state welds. Phase transformation modeling of the real-time $\alpha \rightarrow \beta$ transformation data for CP titanium welds were performed to investigate different possible mechanisms for this phase transformation. The results showed that the phase transformation was controlled by the transport of $\mathrm{Ti}$ atoms across the $\alpha / \beta$ interface in this system. In addition, realtime evolution of grain structure within the entire heat affected zone was modeled in three dimensions using a Monte Carlo technique. The modeling work was performed in collaboration with Professor DebRoy's group at the Pennsylvania State University.

\section{Spatially Resolved X-Ray Diffraction (SRXRD) Highlights}

The SRXRD technique has been developed and refined to the point where it is now a routine experimental technique to apply. Bringing the SRXRD technique on line required several welding-related challenges to be overcome during the first years of this program :1) development of an experimental welding technique that could be used in a confined $x$ ray radiation hutch and could produce welds of sufficient duration to make phase mapping possible, 2) development of an environmental chamber to completely enclose the welding setup in order to completely exclude air from reacting with the hot metal surface, 3 ) development of a method to jog a quasi-stationary weld with respect to the $\mathrm{x}$-ray beam, 4) development of an inert gas side jet to remove condensed metal vapors from the region where the $x$-rays were probing the HAZ, 5) development of a reliable 
method for remotely initiating the arc weld in the high ionization potential helium gas used inside the welding chamber, and 6) development of a visual monitor to observe the weld during the experiment. These refinements to the original proof-of-principal experimental setup were sequentially added over the initial years of this program.

Additional synchrotron-related challenges were overcome throughout this period as well which included: 1) accurate positioning of the xray beam with respect to the welding electrode, 2) optimization of diffracted beam intensity off of the cylindrical specimens, 3 ) optimization of beam flux through small pinhole apertures, and 4) rapid x-ray data acquisition. The current, optimized, experimental setup for welding is described in reference [6], which highlights the first phase map of a weld $H A Z$ ever produced. These experiments investigated $\mathrm{CP}$ titanium using a 2- inch long photodiode detector array to acquire the diffracted beams in real time. This method works very well and still represents the core of our $\mathrm{x}$-ray detection method. Experiments performed with imaging plates worked well on room temperature test samples, however, the Soller slit assembly proved to be too cumbersome to use during welding, did not provide enhanced spatial resolution. Also, imaging plates do not have the time resolution and reat time data display needed for our welding investigation [4].

The second alloy system investigated with SRXRD was AISI 1005 carbon manganese steel, which is a more complex alloy system than that of titanium. This alloy system is very near that of pure iron but has the added prominent effects of carbon, which diffuses interstitially at high rates. Results of these real time observations of the phases present in the HAZ were used to construct a phase transformation map that identified 5 principal phase regions between the liquid weld pool and the unaffected base metal, including the first time that the high temperature delta ferrite phase has been directly observed in steels during welding [1]. These SRXRD experimental results were then combined with a heat flow model of the weld to investigate transformation kinetics under both positive and negative temperature gradients in the HAZ, and then numerically modeled to investigate the kinetics of the ferrite to austenite transformation in more detail [19].

The third alloy system investigated with SRXRD was a duplex stainless steel alloy containing $22 \mathrm{Cr}$ and $5 \mathrm{Ni}$ (alloy 2205), where ferrite $(\delta)$ and austenite $(\gamma)$ transformations in the heat affected zone of a gas tungsten arc weld were observed in real time. The SRXRD data was analyzed to create the first direct quantitative phase map ever obtained and produced of a weld $H A Z[8,12]$. Results revealed that during heating, $\delta$ and $\gamma$ both show signs of annealing as temperatures approach $550^{\circ} \mathrm{C}$, above which the $\delta$ phase then begins to transform to $\gamma$ as temperatures approach $700^{\circ} \mathrm{C}$. Although supported by thermodynamic calculations, the $\delta \rightarrow \gamma$ transformation during heating had not been observed directly until now. Figure 1 shows one of the results of this study where 9 individual regions of the $\mathrm{HAZ}$ were identified heating and cooling cycles of the $\mathrm{HAZ}$ during welding of the 2205 alloy $[8,12]$. This schematic map was created from over 700 diffraction patterns that were analyzed using custom developed profile analysis software routines. 


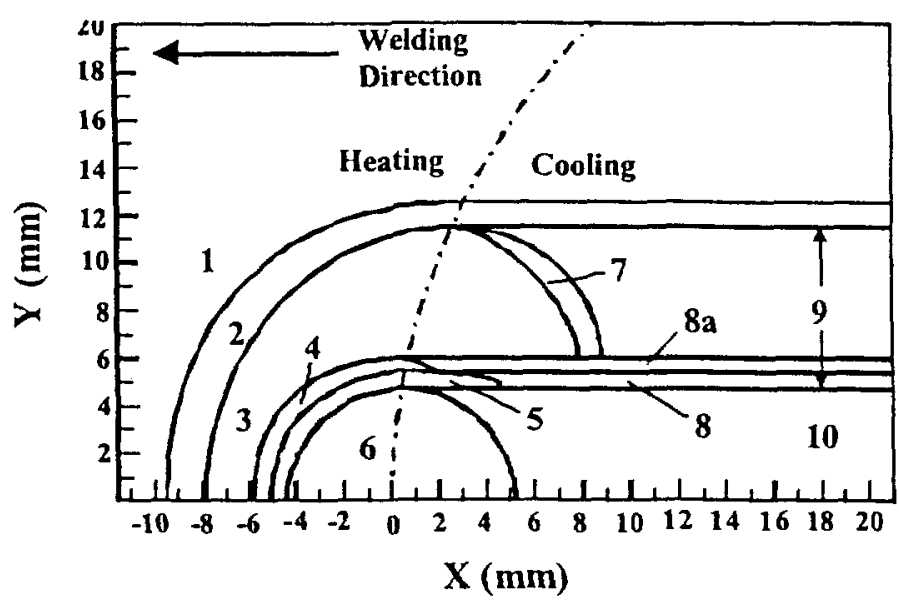

Figure 1: Schematic of the HAZ phase transformation and annealing boundaries in the duplex stainless steel weldment from SRXRD data: 1) base metal, 2) annealing, 3) ferrite decreasing, 4) ferrite increasing, 5) single phase ferrite, 6) liquid, 7) ferrite increasing, 8) nucleation and growth of austenite, 8a) growth of existing austenite, 9) final $\mathrm{HAZ}$, 10) final $\mathrm{FZ}$.

\section{Time Resolved X-Ray Diffraction (TRXRD) Highlights}

The first alloy system investigated using TRXRD was an austenitic stainless steel, AISI Type 304. Real time investigations of solidification and solid state phase transformations were performed at $50 \mathrm{~ms}$ intervals from both the $\mathrm{FZ}$ and $\mathrm{HAZ}$ of stationary welds. Results of these synchrotron experiments were the first to show that solidification can occur directly to $\delta$ ferrite in austenitic stainless steel alloys $[3,16]$. The delta ferrite phase persisted as a single phase for $500 \mathrm{~ms}$, and upon further cooling, the $\delta \rightarrow \gamma$ phase transformation followed, and was largely completed in $200 \mathrm{~ms}$ by the time the weld had cooled to $1100^{\circ} \mathrm{C}[3,16]$. The kinetics of these phase transformations will be further investigated in collaboration with Penn State University.

The second alloy system investigated using TRXRD was a high aluminum containing carbon manganese steel deposited a self-shielded flux cored arc welding (FCAW) technique. This work, in collaboration with Dr. Suresh Babu of ORNL, investigated the FCAW alloy under the high cooling rates produced by stationary arc welds. These conditions are different from the normal moving weld conditions where delta-ferrite forms as the primary solidification phase. The cooling rates of the stationary welds used in this study were on the order of $1000 \mathrm{C} / \mathrm{s}$, which is $10 \mathrm{x}$ higher than the cooling rates of moving welds and were high enough to induce the formation of the non-equilibrium primary austenite phase during solidification [13]. Figure 2 shows one of the TRXRD results from this study. This figure is composed of over 500 diffraction patterns, and reveals that an unexpected non-equilibrium face-centered-cubic (fcc) phase forms directly from the liquid weld pool of the FCAW alloy, as soon as the arc is extinguished. This fcc phase is then observed transforming to the body-centered-cubic (bcc) phase at lower temperatures [13]. These first direct observations of non-equilibrium solidification in this electrode composition, combined with computer modeling and post weld microstructural characterization, are being used by ORNL and the Lincoln Electric Company to help design new self shielded FCAW welding electrodes with improved arc welding characteristics and with improved weld properties. 


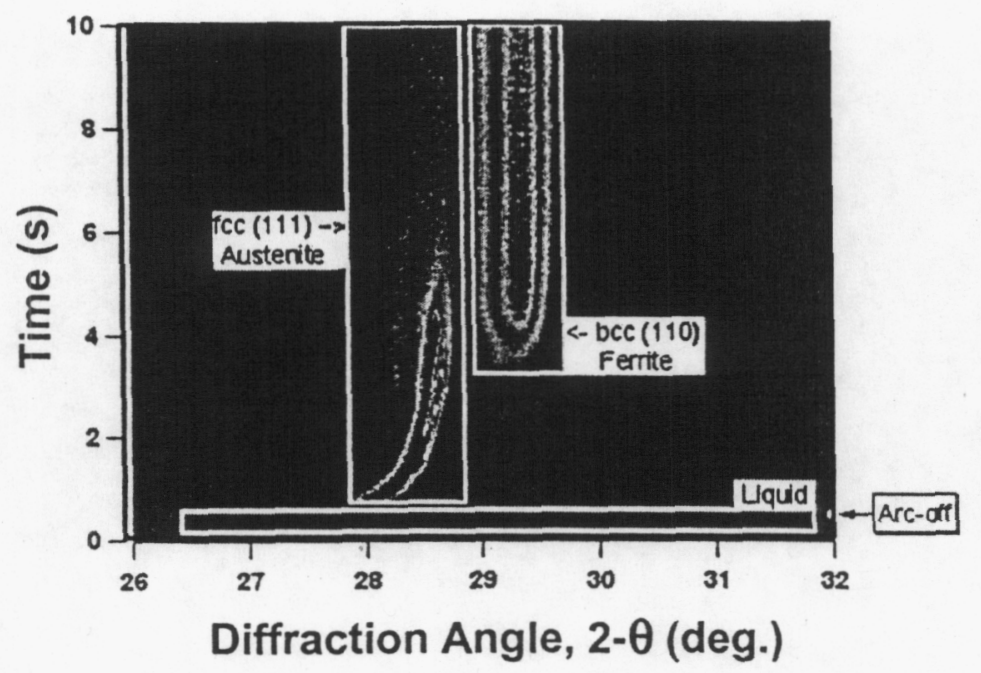

Figure 2: Transient weld solidification and cooling is observed in-situ using the TRXRD technique. Results show solidification to a nonequilibrium FCC phase and subsequent solid state phase transformation to the $\mathrm{BCC}$ phase. The material is a mild steel FCAW consumable welding electrode.

\section{Numerical Weld Modeling Highlights}

By themselves, the SRXRD phase maps and TRXRD investigations of weld solidification and phase transformations represent a major step. These data provide real time and real space phase transformation information necessary to understand microstructural evolution of welds. What is not apparent from these experimental data is the significant and valuable phase transformation kinetics that can be extracted from them. This requires analysis of the experimental data with the aid of modern computational science tools. For this purpose, the Penn State University team modified and applied a 3dimensional coupled heat and fluid flow model previously developed with OBES support to calculate: 1) thermal cycles at specific phase boundaries relevant to the synchrotron based experimental data, 2) grain size distribution and topological information as a function of time in 3-dimensional space, and most importantly 3) phase transformation kinetics and mechanisms.

One example of our numerical modeling work on CP titanium is illustrated in Figure 3, which shows the grain structure evolution and fusion zone formation in 3-dimensions as the material passes under the welding heat source at a constant welding speed. The mechanism behind solid-state phase transformations in this system were further studied by combining the Johnson-Mehl-Avrami (JMA) phase transformation approach, the coupled thermal-fluids model, and the SRXRD experimental observations. It was shown that the $\alpha-\mathrm{Ti}$ to $\beta$-Ti phase transformation is controlled by the transport of $\mathrm{Ti}$ atoms across the $\alpha-\mathrm{Ti} / \beta$-Ti interface. In addition, the Ti HAZ microstructure also was shown to undergo significant grain growth during the weld heating cycle, and this grain growth effect was analyzed for the first time in three dimensions during welding using Monte Carlo type calculations. 
Apart from being a contribution to the developing quantitative knowledge base in fusion welding, this OBES funded collaboration in welding research at Penn State contributed significantly to the education and development of several $\mathrm{PhD}$ students that have gone on to take responsible research positions in leading American institutions.

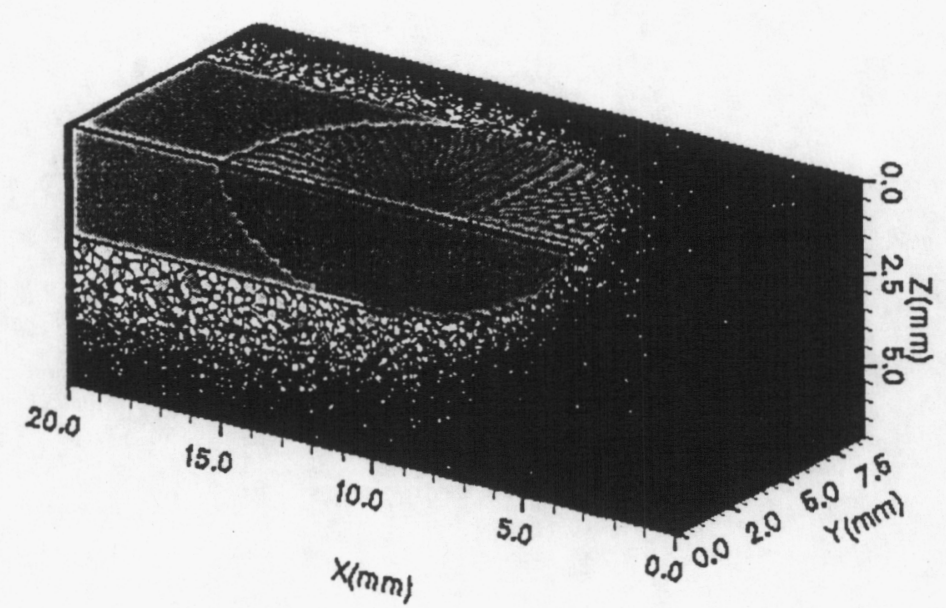

Figure 3: A 3-D coupled thermat fluids numerical model with turbulent convection is used to calculate the fusion zone size and shape, and temperature gradients in the HAZ. These results are further coupled to a 3-D Monte Carlo simulation to predict grain growth in real time in the weld HAZ. Material shown is commercially pure titanium.

\section{Section B: Summary of Proposed Research, FY02-FY04}

With SRXRD mapping now complete for three alloy systems (CP titanium, AISI 1005 steel, 2205 DSS), we plan to focus our experimental work during FY01 on timeresolved experiments. TRXRD investigations of non-equilibrium solidification in the FCAW alloy will continue with ORNL, and will be directed at researching the effect of aluminum content on solidification modes. In addition, TRXRD experiments will be performed to provide additional phase transformation kinetic information for the AISI 1005 steel and 2205 DSS alloys in support of the recently completed SRXRD maps. We plan preliminary work to investigate a new alloy system, Ti-6Al-4V, using both SRXRD and TRXRD techniques. Numerical modeling work will be initiated to develop a transient three-dimensional, turbulent heat transfer and fluid flow model to calculate the rapid thermal excursions that occur during the TRXRD spot welding experiments. Finally, we have ordered and will be receiving a new $\mathrm{x}$-ray detector that covers twice the $2 \theta$ range of our previous detectors. This detector will provide additional diffraction information for observing welding induced phase transformations in-situ and in real time. Synchrotron-based experimental techniques 
With the SRXRD and TRXRD techniques developed we have completely mapped the HAZ phase transformations in three alloy systems (CP titanium, carbon-manganese steel, duplex stainless steel), and have investigated several others. We plan to focus much of the FY02 program on acquiring new synchrotron based experimental data, as described below, since the high flux wiggler beam line at SSRL was down in FY01 due to hardware problems, and since it will also be down in FY03 during the SPEAR-3 upgrade program. In FY03 we plan to analyze the new data acquired during FY02, and during FY04 we will resume experiments on the upgraded SSRL synchrotron, which will have significantly enhanced beam brightness that will contribute to higher spatial and temporal resolution in both the SRXRD and TRXRD data in the future.

With SRXRD and TRXRD becoming routine experiments for us, we now plan only incremental modifications to these techniques. One area of modification will be to develop $x$-ray detection for a wider angle of $2 \theta$ data acquisition. Working with Roper Scientific, we have procured a new one-of-a-kind 4 inch photodiode array $x$-ray detector that doubles our $2 \theta$ range and still retains the capability for fast diffraction pattern capture. This detector is considerably larger in physical dimensions, requiring considerable changes to be made to the existing environmental chamber. However, when completed, our new experimental facility will be able to capture $x$-ray diffraction patterns during welding as rapidly as 20 diffraction patterns per second, and will have an expanded $2 \theta$ range with 1.5 to $2.0 \mathrm{x}$ increate in angular resolution. This new detection scheme will provide us with enhanced quantification, and will be tested during FY02. In addition, we plan to purchase a new infrared camera for real time observations of the weld during the synchrotron experiments. This camera will be procured, set up and tested during FY02.

\section{New TRXRD Synchrotron Experiments}

TRXRD experiments of solidification and solid state phase transformations have proved to be extremely valuable in observing transient phase transformation behavior during the rapid weld heating and cooling conditions of stationary welds with transient thermal response. This experimental technique opens up new possibilities for us by being able to be applied to smaller sample sizes, having the ability to observe phase transformations under a wider range of heating and cooling rates, and being able to investigate solidification phenomena as well as solid state phase transformations in HAZs. Our recent work on flux cored arc welding electrodes in collaboration with ORNL will continue in this area to further research the effect of aluminum and carbon content on the microstructure of these commercially important welding consumables.

New TRXRD experiments will be conducted on the 2205 duplex stainless steel alloy and the AISI 1005 carbon manganese steel to provide additional kinetic phase transformation information in support of the recently completed SRXRD weld phase transformation maps of these alloys $[8,12,5]$. We also plan TRXRD investigations of two new alloy systems, Ti-6Al-4V, and a Nibase superalloy. This will extend our experimental 
capabilities into more complex phase systems and explore the transformations that occur in more highly alloyed and complex materials than we have studied in the past.

\section{Section C: Collaborations}

Collaborations with Penn State University and Oak Ridge National Laboratory

Real advances in welding science require a multi-disciplinary approach to solve the complex materials phenomena that occur under the non-isothermal and severe thermal processing conditions of welds. The computational tools developed and applied through our collaborations with the Penn State University and Oak Ridge National Laboratory are useful in making such welding research problems tractable. The value of these collaborations was recently recognized in the form of the William Spraragen Award from the American Welding Society, which acknowledged one of our papers [5] as the best paper published in the Welding Journal Research Supplement in the year 2000. During the next three years of this program we plan to emphasize these collaborations to an even greater extent, drawing on more graduate students at Penn State University and working more closely with Dr. Suresh Babu and Dr. John Vitek of Dr. Stan David's group at Oak Ridge National laboratory.

\section{Numerical Modeling (Penn State University)}

Numerical modeling work will be directed at developing a transient three dimensional, turbulent heat transfer and fluid flow model to calculate the rapid thermal excursions that occur during the TRXRD stationary welding experiments. This model is significantly more complex that the existing model developed by PSU for moving weld conditions since the weld pool never attains a steady state size or shape. As an example of the complexity of the transient weld model, preliminary versions of this code have been developed and run by Penn State, and are requiring 1.5 days of computational time to solve one transient weld problem, as compared to 1.5 hours to calculate one quasistationary weld problem for the moving weld condition. Once developed, the transient weld model will be used to calculate the temperature and fusion zone geometry as a function of weld time in the FZ and HAZ to help analyze the results of the TRXTD synchrotron experiments. Here we plan to use this model to calculate temperature distributions around stationary welds in the FCAW electrode composition(s), 2205 duplex stainless steel, $1005 \mathrm{C}-\mathrm{Mn}$ steel, Ti-6AL-4V, and Ni-based superalloy.

Phase transformation modeling will continue at PSU using the combined results of the coupled thermal fluids model(s), the JMA phased transformation analysis, and the synchrotron-based experimental results to develop kinetic parameters for phase transformations in all materials alloy systems being studied. This approach has already been successfully used to analyze SRXRD results form CP titanium [5]. New JMA phase transformation work will be applied to the new semi-quantitative HAZ SRXRD maps developed for the duplex stainless steel alloy $[8,12]$ and the $1005 \mathrm{C}-\mathrm{Mn}$ steel alloy [9]. 
The kinetic studies of phase transformations during rapid heating and cooling produced during stationary 'spot' welds will also be initiated. Initially, the TRXRD experimental results obtained in the 304 stainless steel alloy $[3,16]$ will be investigated further with numerical modeling. These calculations will seek to develop kinetic parameters for the bcc (ferrite) to fcc (austenite) transformation during both the heating and cooling cycles of the weld. This same type of approach will then be used to calculate kinetic parameters from the TRXRD results acquired on 1005 C-Mn steel. Since we already have mapped the 1005 steel HAZ using SRXRD [1], the results of the TRXRD experiments will provide additional experimental information about the kinetics of phase transformation in steels. The combination of the SRXRD map, the TRXRD data, and numerical modeling will allow us to get at the kinetics from two different experimental methods and for different welding conditions, thus giving us the ability so see how the welding conditions affect the phase transformation mechanisms in this very important alloy system.

Monte Carlo calculations of grain growth in the HAZ of welds were successfully applied in three dimensions to the $\mathrm{CP}$ titanium alloy [2]. This computational technique will be refined and applied to other alloy systems, such as $1005 \mathrm{C}-\mathrm{Mn}$ steels and Ti-6Al-4V. In addition, the Monte Carlo technique will be used to provide the basis for investigating some of the basic assumptions originally used to develop the JMA expressions for phase transformations in alloys.

\section{Non-equilibrium solidification, thermodynamics and characterization (ORNL)}

Direct observations of non-equilibrium solidification of the FCAW electrode composition have demonstrated the power of the TRXRD technique for real time observations of phase transformations under high heating and cooling rates. This work will be continued, and emphasized, to investigate the influence of aluminum and carbon on the solidification and solid-state phase transformations in the Fe-C-Al system. Here we will depart slightly from the commercial FCAW alloy welding electrode and concentrate on the ternary alloy system, where we have more control over the composition and initial base metal starting microstructure. Alloys will be produced with controlled $\mathrm{Al}$ and $\mathrm{C}$ concentrations. This will help us to investigate the interplay between these elements and to study their effects on solidification and solid-state phase transformations. These studies will account for the different partitioning behavior of $\mathrm{C}$ and $\mathrm{Al}$ between the solid and liquid phases, their different diffusivities in the solid state, and their different effects on austenite and ferrite phase stability in this Fe-based steel alloy system.

Thermodynamic calculations of phase stability and partitioning play a critical role in all of the phase transformation modeling schemes. ORNL will use Thermocalc to calculate phase equilibria and element partitioning in all alloy systems being investigated. Numerical modeling of weld temperature distributions, liquid/solid interface velocities, and temperature gradients at the liquid/solid interface are also important for this investigation of solidification dynamics, and will be calculated by the Penn State team, as described above. 
We plan to extend tour TRXRD work into a new alloy system for us in order to study disorder solute trapping in nickelbase superalloys. The effects of solidification rate on the microstructure of nickelbased super alloys containing aluminum is an important field of research and has been studied by ORNL and others using conventional metallurgical techniques. From this previous work one concludes that the primary solidification of L12 ordered $\gamma^{\prime}$ phase formation is stifled in these alloys due to trapping of disorder with increase in solidification velocity (W. J. Boettinger and M. J. Aziz, Acta Metallurgica 37, p3379, 1989). However, there are no direct observations of disorder trapping phenomena. Here we plan to use in-situ TRXRD to study the disorder trapping in NiAl, $\mathrm{Ni}-\mathrm{Al}-\mathrm{Cr}, \mathrm{NiAl}-\mathrm{Ti}$ systems under different weld cooling conditions produced by stationary arc welding methods. The formation of $\gamma$ (FCC) phase, $\gamma^{\prime}$ (L12 ordered precipitates), $\beta$ (NiAl) or potential disordered $\beta$ phase will be evaluated. The above basic research has commercial as well as research importance for the processing of new class of nickel base superalloys to be used in energy industries.

\section{Section D: Scientific Collaborations}

We have ongoing collaborations with Professor DebRoy's group at the Penn State University (past 4 years) and with Dr. Stan David's group at Oak Ridge National Laboratory (past 2 years). Both collaborators are also funded by OBES/DMS for performing welding research, and are working in the areas of coupled thermat-fluids modeling of welds (PSU), application of phase transformation kinetic models (PSU, ORNL), thermodynamic calculations (ORNL) and microstructural characterization of welds (ORNL). The William Spraragen Award received in 2000 was awarded for a paper written jointly by PSU and LLNL. In addition, we collaborate with T. Ressler, Fritz-Haber Institute, Berlin, Germany, and A.C. Thompson, LBNL, for SRXRD/TRXRD experiments and instrumentation development respectively.

\section{Section E: Representative Publications, FY98-FY01}

Listed below are nine publications representative of our recent work. These publications are arranged into four groups to highlight the different aspects of this program and our different collaborations.

\section{Group 1}

The first four papers highlight the results of our SRXRD phase mapping studies in three different alloy systems: carbon manganese steels, commercially pure titanium, and duplex stainless steel.

- J. W. Elmer, Joe Wong and Thorsten Ressler, "Spatially Resolved X-Ray Diffraction Mapping of Phase Transformations in the HAZ of Carbon-Manganese Steel Arc Welds," Metall. and Mater. Trans. A, 32A (5), pp. 1175-1187, 2001. 
- J. W. Elmer, Joe Wong and Thorsten Ressler, “ Spatially Resolved X-Ray Diffraction Phase Mapping and $\alpha \rightarrow \beta \rightarrow \alpha$ Transformation Kinetics in the HAZ of Commercially Pure Titanium Arc Welds," Metall. and Mater. Trans. A, 29A(11), p. 2761, 1998.

- Thorsten Ressler, Joe Wong and J. W. Elmer, “ Investigation of RealTime Microstructure Evolution in Steep Thermal Gradients using Spatially Resolved Xray Diffraction: A Case Study for Ti Fusion Welds," J. Phys. Chem. B, 102(52), p. 10724, 1998.

- T. A. Palmer, J. W. Elmer, and Joe Wong, "In-Situ Observations of Phase Transformations in the HAZ of 2205 Duplex Stainless Steel Weldments," submitted to ASM International: Joining of Advanced Specialty Materials IV, 2001.

Group 2

The next two papers highlight the results of ou TRXRD experiments in two additional alloy systems: 1) AISI Type 304 austenitic stainless steel, and 2) a Fe-C-Al-Mn Low Alloy Steel deposited by a flux cored welding technique. The FCAW publication is representative of our collaboration with Oak Ridge National Laboratory, and is the first of several papers that will be published on the topic of non-equilibrium solidification observed by TRXRD.

- S. S. Babu, J. W. Elmer, S. A. David and M. Quintana, "In-Situ Observations of Non-equilibrium Austenite Formation During Weld Solidification of a Fe-C-AlMn Low Alloy Steel," in press Proceedings of the Royal Society: Mathematical, Physical and Engineering Sciences, July, 2001.

- J. W. Elmer, Joe Wong and Thorsten Ressler, "In-Situ Observations of Phase Transformations During Solidification and Cooling of Austenitic Stainless Steel Welds using Time-Resolved X-Ray Diffraction," Scripta Materialia, 43(8), pp. $751-757,2000$.

Group 3

The next two papers represent the work that we are doing in coupled thermal-fluids modeling of welds and kinetic modeling of phase transformations that occur during welding. Both of these papers were performed in collaboration with the Penn State University. The Welding Journal paper received the William Spraragen Award from AWS in 2000 . 
- Z. Yang, J. W. Elmer, Joe Wong, and T. DebRoy, "Evolution of Titanium Arc Weldment Macro- and Microstructures - Modeling and Real Time Mapping of Phases," Welding Journal, 79(4), p. 97s-112s, 2000.

- Z. Yang, S. Sista, J. W. Elmer, and T. DebRoy,'Three Dimensional Monte Carlo Simulation of Grain Growth During GTA Welding of Titanium," Acta Metall. Mater, 48 (12), pp. 4813-4825, 2000.

\section{Group 4}

The last paper represents an instrumentation technique developed for potential app;lication to welding research.

- Joe Wong, P. A. Waide, J. W. Elmer and A. C. Thompson, "Spatially Resolved Diffraction using a Soller Collimator-Imaging Plate Assembly," Nucl. Instrum. Meth. A, 446(3), p. 581-591, 2000. 


\section{Appendix: Publications, FY98-FY01}

\section{Peer Reviewed Journal Publications FY98-FY0I}

1. J. W. Elmer, Joe Wong and Thorsten Ressler, "Spatially Resolved X-Ray Diffraction Mapping of Phase Transformations in the HAZ of Carbon-Manganese Steel Arc Welds," Metall. and Mater. Trans. A, 32A (5), pp. 1175-1187, 2001.

Z. Yang, S. Sista, J. W. Elmer, and T. DebRoy,"Three Dimensional Monte Carlo Simulation of Grain Growth During GTA Welding of Titanium," Acta Metall. Mater, 48 (12), pp. 4813-4825, 2000.

3. J. W. Elmer, Joe Wong and Thorsten Ressler, "In-Situ Observations of Phase Transformations During Solidification and Cooling of Austenitic Stainless Steel Welds using Time-Resolved X-Ray Diffraction," Scripta Materialia, 43(8), pp. 751$757,2000$.

4. Joe Wong, P. A. Waide, J. W. Elmer and A. C. Thompson, "Spatially Resolved Diffraction using a Soller Collimator-Imaging Plate Assembly," Nucl. Instrum. Meth. $A, 446(3)$, p. 581-591, 2000.

5. Z. Yang, J. W. Elmer, Joe Wong, and T. DebRoy, "Evolution of Titanium Arc Weldment Macro- and Microstructures - Modeling and Real Time Mapping of Phases," Welding Journal, 79(4), p. 97s-112s, 2000.

6. J. W. Elmer, Joe Wong and Thorsten Ressler, “ Spatially Resolved X-Ray Diffraction Phase Mapping and $\alpha \rightarrow \beta \rightarrow \alpha$ Transformation Kinetics in the HAZ of Commercially Pure Titanium Arc Welds," Metall. and Mater. Trans. A, 29A(11), p. 2761,1998

7. Thorsten Ressler, Joe Wong and J. W. Elmer, " Investigation of RealTime Microstructure Evolution in Steep Thermal Gradients using Spatially Resolved X-ray Diffraction: A Case Study for Ti Fusion Welds," J. Phys. Chem. B, 102(52), p. 10724 , 1998.

\section{Publications in Press and Other Publications FY98-FY01}

8. T. A. Palmer, J. W. Elmer, and Joe Wong, "In-Situ Observations of Phase Transformations in the HAZ of 2205 Duplex Stainless Steel Weldments," to be submitted to ASM International : Joining of Advanced Specialty Materials IV, 2001.

9. W. Zhang, J. W. Elmer, and T. DebRoy, "Modeling and Real Time Mapping of Phases during GTA Welding of 1005 Steel," submitted to Materials Science and Engineering, August, 2001. 
10. Time and Space-Resolved X-ray Diffraction, Joe Wong, in Synchrotron Radiation Applications to Materials Science, edited by Phillip Sprunger, CAMD/LSU Publishers, (2001) Chap. 18. (Invited paper).

11. Chemical Dynamics and Phase Transformation in High Temperature Processes using TRXRD and SRXRD, Joe Wong, in Chemical Applications of Synchrotron Radiation" ed. T.K. Sham, World Scientific Publishing Company, (2001), in press. (Invited paper)

12. T. A. Palmer, J. W. Elmer, and Joe Wong, "In-Situ Observations of Ferrite/Austenite Transformations in Duplex Stainless Steel Weldments Using Synchrotron Radiation," UCRL-JC-143682, submitted to Science and Technology of Welding and Joining, May, 2001.

13. S. S. Babu, J. W. Elmer, S. A. David and M. Quintana, "In-Situ Observations of Non-equilibrium Austenite Formation During Weld Solidification of a Fe-C-Al-Mn Low Alloy Steel," in press Proceedings of the Royal Society: Mathematical, Physical and Engineering Sciences, July, 2001.

14. Joe Wong, E. M. Larson, J. B. Holt, T. Ressler and J. W. Elmer, "In-Situ Chemical Dynamics and Phase Mapping under Steep Thermal Gradients using TimeResolved and Spatially Resolved X-Ray Diffraction," Proceedings of the International Alloys Conference-2, LAC-2, Plenum Press, pp. 285-306, 2001. (Invited paper).

15. Z. Yang, J. W. Elmer, Joe Wong, and T. DebRoy, "A Combined Modeling and Experimental Study of Microstrutural Evolution in Titanium Arc Welds," $A S M$ International : Joining of Advanced Specialty Materials II, pp. 174-183, April, 2000.

16. J. W. Elmer, Joe Wong and Thorsten Ressler, "Direct observation of phase transformations in austenitic stainless steel welds using in-situ spatially resolved and time resolved xray diffraction," ASM International: Joining of Advanced Specialty Materials II, pp. 200-208, April, 2000.

17. J. W. Elmer, Joe Wong, and Thorsten Ressler, "In-Situ Spatially Resolved XRay Diffraction Mapping of the $\alpha \rightarrow \beta \rightarrow \alpha$ Transformation in Commercially Pure Titanium Arc Welds," $5^{\text {th }}$ International Conference on Trends in Welding Research, Pine Mountain, GA, p. 107, June, 1998. 
Materials Science Dept. Seminar, Louisiana State University, Baton Rouge, LA "In-situ phase transformation and mapping in Materials Science: Combustion synthesis with TRXRD and Fusion Welds with SRXRD" (Feb/98)

ALS X-ray Science and Technology Seminar, ALS, Berkeley, CA "Real time chemical Dynamics and Phase Transformation using TRXRD and SRXRD" (May/98)

Materials Science Seminar, National Institute for Research in Inorganic Materials, Tsukuba, Japan "In-situ Phase Mapping and Microstructural Evolution in Steep Thermal Gradients using SRXRD (Nov/98)

Plenary Lecture, $5^{\text {th }}$ Symposium on Science and Technology and Annual Users Meeting CAMD, Louisiana State University, Baton Rouge, LA "Synchrotron-based Materials Science and New Opportunities at CAMD" (May/99)

$2^{\text {nd }}$ International Alloy Conference, IAC-2, Davos Switzerland, "In-situ Chemical Dynamics and Phase Transofrmation under Steep Thermal Gradients using TRXRD and SRXRD" (Aug/99)

Physics Department Seminar, University of Messina, Messina, Sicily, Italy Chemical dynamics and phase transformations using in-situ synchrotron techniques" (Apr/00)

CAMD summer school on Synchrotron Radiation, CAMD, Baton Rouge "Time-resolved and spatially resolved diffraction in materials dynamics investigations" (Jun/00)

Materials Science Kolloquims, University of Wuppertal, Wuppertal, Germany, "Novel Applications of Synchrotron Radiation in Materials Science" (Jul/00)

International Workshop on the TESLA-XFEL on Hard Condensed Matter - A Scientific Case HASYLAB at DESY, Hamburg, Germany, In-situ Time Resolved and Spatially resolved Materials Dynamics" (Jul/00) 


\section{Section F: CURRICULUM VITAE}

\section{John W. Elmer}

\section{MAJOR SCIENTIFIC DISCIPLINES}

Metallurgy, materials joining, microstructural evolution during thermal processing of metals and alloys, kinetics of non-isothermal phase transformations, electron-beam and laser-beam joining, rapid solidification processing

\section{EDUCATION}

Massachusetts Institute of Technology

Sc.D : Degree in Metallurgy, September, 1988.

Colorado School of Mines

Cambridge, MA

MS : Degree in Metallurgical Engineering, December, 1981.

BS : Degree in Metallurgical Engineering, May, 1979.

\section{EMPLOYMENT HISTORY}

\section{Lawrence Livermore National Laboratory}

\section{Livermore, CA}

Deputy Program Element Leader, Materials Science and Technology Division (4/98 to present)

Deputy Program Element Leader for Joining and Stockpile Metallurgy. Manage the joining group, which is responsible for materials-joining $R \& D$ in support of the major laboratory programs using precision electron-beam welding, laser-beam welding and cutting, vacuum brazing, and diffusion bonding. Principal Investigator: DOE/Office of Basic Energy Sciences new-initiative research grant to investigate weld HAZ phase transformation kinetics using synchrotron radiation and in situ Spatially Resolved X-Ray Diffraction, since 1996.

\section{Metallurgist and Principal Investigator, Materials Science and Technology Division}

\section{(5/92 to $4 / 98)$}

Established and managed CRADAs between: 1) The Boeing Corporation and LLNL for laser welding of titanium alloys for superplastic forming of aerospace structures, and 2) A Partnership for New Generation Vehicles (PNGV) consortium of automotive companies for laser welding of microduplex stainless steel alloys for the manufacture of exhaust system components. Developed brazing techniques for joining ultra-flat diamond turned copper substrates for applications to accelerator physics. Developed and patented a method for computer assisted tomographic imaging of electron beams for use in measuring the power density distribution in high power electron beams used in welding.

Group Leader, Materials Division 
to $5 / 92$ )

Group leader of Materials Joining. Managed the joining group which was responsible for materials-joining R\&D in support of the major laboratory programs (energy, weapons, strategic defense) using precision electron-beam welding, laser-beam welding, surface modification, vacuum brazing, and diffusion bonding.

\section{Post-Doc, Materials Division (Joining Group)}

\section{to 8/89)}

Post-Doc., conducting materials research to investigate rapid solidification of $\mathrm{Al} B \mathrm{Be}$ alloys, and microstructural evolution during rapid solidification of stainless steel alloys. Techniques used included electron-beam welding, computer modeling of the thermodynamics and kinetics of rapid solidification and microstructural characterization using optical microscopy and TEM.

\section{Graduate Student in the Materials Science and Engineering Dept., MIT} to $9 / 88$ )

Graduate student, conducting research in microstructural evolution during solidification of welds. Experience with heat flow modeling in welds, materials characterization using VSM, XRD, EPMA, SEM, and materials processing by electron beam re-solidification and melt spinning. Received Doctorate degree in Metallurgy, September, 1988, under Professor T. W. Eagar.

Metallurgist in the Materials Division (Joining Group), LLNL

\section{to $9 / 84$ )}

Staff member, responsible for conducting materials joining R\&D using EBW, GMAW, LBW, FB, DFW, and FRW techniques. Projects included metallurgical investigations of hot-cracking, sensitization, grain growth, brazeability, and the mechanical properties of diffusion-welded joints. Materials included stainless steel, aluminum, titanium, refractory alloys $(\mathrm{V}, \mathrm{Ta}$ and $\mathrm{W})$, electrical grade alloys $(\mathrm{Cu}$ and $\mathrm{Ag}$ ), ceramics, and toxic/radioactive materials (Be, $\mathrm{U}, \mathrm{Pu}$ ).

\section{National Bureau of Standards Boulder, $\mathrm{CO}$}

Metallurgist, Fracture and Deformation Division

to $1 / 82$ )

Part-time staff member, responsible for cryogenic mechanical testing of alloys and weldments. Conducted tensile, J-integral, and fatigue-crack-growth-rate experiments on aluminum alloys, experimental austenitic stainless steels, and manganesestabilized austenitic alloys for use in magnetic fusion energy systems.

\section{PROFESSIONAL AND PERSONAL INFORMATION}

\section{Professional Status}

- Registered Professional Engineer in Colorado, license No. 22131.

- Registered Metallurgical Engineer in California, license No. MT001784. 
Professional and Technical Committees

Active Committee Memberships

- Member : ASM Henry Marion Howe Medal and Marcus A. Grossmann Award Selection Committee, 2001.

- Chairman: Technical Awards Committee for the American Welding Society, 2000 to present

- Member : Technical Papers Committee for the American Welding Society, 1999 to present

- Member : Fusion Welding sub-committee of the ASM Joining Committee, 1999 to present

- Principal Reviewer : Welding Journal Research Supplement, 1998 to present

- Member Editorial Board : Science and Technology of Welding and Joining, 1996 to present

- Key Reader : Metallurgical and Materials Transactions A, 1991 to present

Past Committee Memberships

- Expert Member/Vice Delegate : American Council of the International Institute of Welding on Commission IV (High Energy Density Processes) 1998/1999.

- Member : Technical Awards Committee for the American Welding Society, 1998 to 1999

- Vice-Chairman/Chairman : Board of Review for Metallurgical and Materials Transactions A, 1996/1997

- Reviewer : Welding Journal Research Supplement, 1989 to 1998

\section{Professional Affiliations}

- Member : Tau Beta Pi, Sigma Xi, and Alpha Sigma Mu

- Member : American Society for Metals, and American Welding Society

\section{Honors and Awards}

- William Spraragen Award (2001) from the American Welding Society.

- Elected Fellow of the American Welding Society, class of 2000

- Professor Masubuchi-Shinsho Corporation Award (1995) from the American Welding Society.

- William Spraragen Award (1991) from the American Welding Society.

\section{U. S. Patents}


$5,382,895$ (January 17, 1995); 5,468,966 (November 21, 1995); 5,534,677 (July 9 , 1996)

$5,554,926$ (September 18, 1996); 5,583,427 (December 10, 1996); 6,264,880 (July $24,2001)$

$6,300,755$ (October 9, 2001)

\section{Personal}

Born: Homestead, FL, USA, December 9, 1957.

Security Clearance: active DoE Q

Interests: running, fly fishing, skiing, snowboarding, mountain biking

Languages: Proficient in French

\section{Publications}

Dr. Elmer has over 65 refereed journal articles in this field (Available upon request).

\section{References}

Available upon request

\section{Invited/Keynote Presentations}

- "Tomographic Imaging of Noncircular and Irregular Electron Beam Current Density Distributions", and "Fast Method for Measuring the Power Density Distribution of Non-Circular and Irregular Electron Beams". Presented at the Commission IV annual meeting of the International Institute of Welding, Hamburg, Germany, September, 1998.

- "Analysis of Heat Affected Zone Phase Transformations Using Spatially Resolved XRay Diffraction with Synchrotron Radiation." Presented at the INTSOL96 conference, Trivandrum, India, November 28, 1996.

- Tutorial Lecture "Microstructural Evolution During Fusion Welding." Presented at the INTSOL96 conference, Trivandrum, India, November 26, 1996.

- "Measuring The Ferrite Content Of Rapidly Solidified Stainless Steel Alloys." Presented to the Welding Research Council Subcommittee on the Welding Of Stainless Steels, Manhattan, NY, November, 1988.

- "Diffusion Welding: A Low-Distortion Alternative For Dissimilar Metal Joints." Presented to the joint meeting of the Boston ASM and AWS chapters, Saugus, MA, December, 1986. 


\section{Joe Wong}

Lawrence Livermore National Laboratory, University of California Chemistry and Materials Science

\section{CURRENT POSITION: Senior Staff Chemist}

\section{EDUCATION:}

B.Sc.

Pure and Applied Chemistry, University of Tasmania, Australia, 1965

1966

B.Sc.(1 st Class Hons) Physical Chemistry, University of Tasmania, Australia,

Ph.D. Physical Chemistry, Purdue University, Indiana, 1970

D.Sc. University of Tasmania, Tasmania, Australia, 1986

\section{CAREER AND EXPERIENCE:}

1995-present Consulting Professor, Stanford Synchrotron Radiation Laboratory, Stanford University

1992 Alexander von Humboldt Research Award for Senior US Scientist, Germany

1986-present Senior Chemist: Chemistry and Materials Science,

LLNL

1985 Visiting Scholar at Cambridge University, UK

1970-86 Staff Chemist: $\quad$ GE Research \& Development

Center, Schenectady, NY

\section{RESEARCH INTERESTS:}

Materials science: $\quad$ EXAFS, XANES \& QEXAFS spectroscopy, and Novel Synchrotron instrumentation;

resolved studies;

Chemical dynamics, Phase transformation, Time- \& Spatially-

Environmental materials, 3? damaged fused silica

High resolution electron microscopy \& electron energy loss spectroscopy

Glass science: $\quad$ IR and optical spectroscopy, and glass structure

Coauthored a now classic textbook entitled

"GLASS: Structure by Spectroscopy"

\section{PUBLICATIONS:}

- Over 180 refereed journal articles

- 10 invited review articles

- 7 US patents 
Section Professional Awards and Recognitions

\begin{tabular}{|l|l|l|}
\hline Award/Prize Name & Sponsor & Recipient \\
Fellow, Class of 2000 & American Welding Society & John W. Elmer \\
William Spraragen Award* & American Welding Society & $\begin{array}{l}\text { Z. Yang, J. W. Elmer, Joe } \\
\text { Wong, and T. DebRoy }\end{array}$ \\
Senior STA Fellowship, 1998 & $\begin{array}{l}\text { Science and Technology } \\
\text { Agency, Japan }\end{array}$ & Joe Wong \\
$\begin{array}{l}\text { Consulting Professor, SSRL, Stanford } \\
\text { University 3 }\end{array}$ & Joe Wong \\
\hline
\end{tabular}

* William Spraragen Award -Best Paper published in the Welding Journal Research Supplement during the calendar year 2000. See reference [5]. 